\title{
Climate change, crops and commodity traders: subnational trade analysis highlights differentiated risk exposure
}

\author{
Emilie Stokeld ${ }^{1}$ (D) Simon A. Croft ${ }^{1} \cdot$ Jonathan M. H. Green ${ }^{1} \cdot$ Christopher D. West $^{1}$
}

Received: 30 July 2019 / Accepted: 30 August 2020/Published online: 15 September 2020

(C) The Author(s) 2020

\begin{abstract}
The global food system is increasingly interconnected and under pressure to support growing demand. At the same time, crop production is facing new and uncertain impacts from climate change. To date, understanding how downstream supply chain actors, such as commodity traders, are exposed to climate change risks has been difficult due to a lack of high-resolution climate and trade data. However, the recent availability of supply chain data linking subnational production to downstream actors, and gridded projections of crop yield under climate change, allows us to assess individual commodity trader exposure to long-term climate change risk. We apply such an analysis to soy production in Brazil, the world's largest soy exporter. Whilst uncertainty across crop models' yield projections means it remains difficult to accurately predict how production across the region will be affected by climate change, we demonstrate that the risk exposure of trading actors differs substantially due to the heterogeneity in their sourcing. Our study offers a first attempt to analyze subnational climate risk to individual trading actors operating across an entire production landscape, leading to more precise risk exposure analysis. With sufficient subnational data, this method can be applied to any crop and country combination, and in the context of wider food security issues, it will be pertinent to apply these methods across other production systems and downstream actors in the food system.
\end{abstract}

Keywords Transnational climate impacts · Supply chains $\cdot$ Crop models $\cdot$ Climate risk $\cdot$ Food system $\cdot$ Soybean

Electronic supplementary material The online version of this article (https://doi.org/10.1007/s10584-02002857-5) contains supplementary material, which is available to authorized users.

Emilie Stokeld

emilie.stokeld@york.ac.uk

1 Stockholm Environment Institute - York, Department of Environment \& Geography, University of York, Wentworth Way, Heslington, York YO10 5NG, UK 


\section{Introduction}

The global food system is increasingly interconnected and under pressure to support changing demand and a growing world population. Almost a quarter of all food produced globally for human consumption is traded internationally (D'Odorico et al. 2014), and it is predicted that up to half of the world's population will be dependent on ex situ land and water resources by 2050 (Fader et al. 2013). With the rising demand requiring an estimated $70 \%$ increase in global food production by the middle of the century (Sentelhas et al. 2015), mitigating risks to crop yields will be critical not only to producers and consumers in the region of production, but also to a growing number of downstream actors and international consumers who rely on imported crops.

Crop production is now facing new and uncertain impacts from climate change: increased global mean temperatures, altered rainfall patterns, and more frequent extreme weather events (IPCC 2014). These phenomena will affect crop yields (production per unit area), with specific impacts varying geographically and by crop. Over the past 30 years, the literature on climate risk to agriculture has transitioned from optimism to pessimism (Nelson et al. 2014b); whilst in some cases crop yields are expected to increase under climate change (e.g. Northern Europe, Wheeler and von Braun 2013; root crops, Ramirez-Villegas et al. 2013), generally a decrease in global crop yields is predicted (Rosenzweig et al. 2014; Tai et al. 2014).

However, transnational climate risks, including those linked to trade, are rarely addressed in national climate risk assessments (Challinor et al. 2017; Ciplet et al. 2018). In a recent systematic review of national climate change risk assessments in Europe (EEA 2018), only five countries out of 25 considered "cross-border" risks (e.g. climate-induced migration, water flows, trade), although ten countries recognized that further research on these risks was necessary. At the private sector level, major commodity traders have already recognized the risks and opportunities raised by climate change (e.g. Cargill 2019a; Bunge 2019), but the spatial scale of their analyses is unclear and studies of climate risk exposure across traders are not available in the peer-reviewed literature. Both traders and countries relying on imports could improve their risk assessments and responses with access to fine-scaled data that looks at climate change impacts across their existing supply chains and production landscapes.

Translating production risks to downstream actors is complex and methodological advancements for quantifying transnational climate change impacts have been scarce, but recent progress has been made with the creation of the transnational climate impacts (TCI) index (Benzie et al. 2016; Hedlund et al. 2018). The TCI index expands the concept of climate risk to include variables such as trade openness, cereal import dependency, and embedded water risk. The TCI index provides a more comprehensive global perspective of climate risk than traditional climate vulnerability indicators, exposing hidden linkages of risk which can be explored through transnational risk analysis.

Linking climate risk to downstream actors requires mechanisms to map the supply chains between producing regions and consumption activities. There are different approaches to tracking the flows of goods around the world, from simple material flow analysis (MFA) through to complex life-cycle analysis (LCA), multiregional input-output (MRIO) models and hybrid models linking MFA and MRIO approaches (Croft et al. 2018). The Trase initiative (Trase 2019) provides an advanced material flow analysis which offers high-resolution subnational links between points of production, traders, and destination countries.

These flows can be complemented by environmental extensions to link consumption-driven production to associated environmental impacts. Likewise, projected impacts on production 
can be linked to downstream actors, highlighting their relative exposure to environmental risk. To the best of our knowledge, trade information has not been linked to the subnational level in the context of climate risk exposure to date. If climate change impacts vary at a subnational scale, then downstream actors are likely to experience different levels of transnational risk exposure even when sharing similar national-scale sourcing patterns.

In addition to subnational trade data, a detailed analysis of trade-linked climate risk also relies on the availability of subnational datasets for climate change impacts on crop production. Climate change risks to yield can be classified into two categories: acute risks to yield, which occur as a result of the increasing frequency and magnitude of extreme weather events (Fischer 2009), and chronic risks to yield, which are the gradual changes in yield as a response to changing mean climatic conditions (Challinor et al. 2014). It is reasonable to assume that both acute and chronic risks could vary at a subnational level, particularly in larger and diverse crop-producing countries. In this paper, we focus on chronic climate change risks to yield, for which datasets are more robust (Thornton et al. 2014) and are available at a high resolution appropriate for subnational analysis.

Chronic risks are important for commodity traders to consider when making long-term investments in assets, such as transport infrastructure, grain silos and port terminals. Investment in assets is widespread among agri-commodity traders, and all four of the major "ABCD" grain traders (ADM, Bunge, Cargill and Louis Dreyfus) own physical assets across a range of commodities (Pirrong 2014). For example, the commodity trader Cargill invested more than $\mathrm{R} \$ 300$ million in a grain export terminal in the Brazilian municipality of Santarém which is still in use 15 years later, an investment described as representative of that happening in locations where companies foresee competitive advantage in the long term (Cargill 2019b). These decisions would be affected by chronic risk, and traders have an interest in considering how suitability for crop production will change over the coming decades. In a competitive environment, where yields are expected to decrease in some areas and increase in others (Rosenzweig et al. 2014), traders with assets in future high-yielding areas will have a potential advantage.

Crop models translate climate change projections to changes in crop growth and yield. They play a central role in helping agro-industry, policymakers and plant scientists understand the impacts of climate change (Fodor et al. 2017). Whilst several approaches to crop modelling exist, process-based crop models are the most common choice for climate impact assessments (Tao et al. 2009; White et al. 2011). Originally developed for field-level application, processbased crop models use a combination of inputs such as weather and soil conditions, as well as plant-specific characteristics, to calculate crop yield and other parameters. Several processbased crop model outputs can be compared at once via the Inter-Sectoral Impact Model Intercomparison Project (ISIMIP 2018; Rosenzweig et al. 2014; Warszawski et al. 2014), which coordinates simulation rounds with consistent input data and climate change scenarios across climate-impact modelling groups. By offering a consistent framework for the intercomparison of risk models, ISIMIP provides critical information for adaptive and transformational decision-making across, and within, individual sectors (Rosenzweig et al. 2017).

In this paper, we advance estimates of actor-specific climate risk exposure by drawing on the latest available datasets in climate, crop and trade modelling described above. We propose a methodology that could detect differences in climate risk exposure between downstream actors in production landscapes where climate change acts heterogeneously, and traders have unique spatial sourcing profiles. Our methods can be applied to countries, crops and downstream supply chain actors for which similar data are available, but here we apply our 
methodology to a case study of commodity traders sourcing soy grown in Brazil, to highlight an example of the differences in relative risk exposure associated with particular supply chains. Brazil is the world's largest soy exporter (Samora 2018), and existing estimates of the impact of climate change on soy in the country suggest heterogeneous effects across its soy-producing areas (Lobell et al. 2008; Osborne et al. 2013; Justino et al. 2013; Rosenzweig et al. 2014). These attributes highlight the need for analysis of connectivity to trade at an appropriate subnational scale, as commodity traders could experience different levels of risk exposure based on the areas within the country from which they source soy. In the following section, we outline the methodology and apply it to the case study of Brazilian soy.

\section{Methods}

\subsection{Modelling overview}

The methods include three modelling components: climate, biophysical and trade (Fig. 1). First, current and future climate data are projected for a range of greenhouse gas concentration scenarios using a global climate model. Second, these climate data are used as an input to crop models to project crop yields under climate change scenarios. Finally, these crop yield projections are linked to Trase supply chain data to quantify traders' relative risk exposure to climate change impacts on crop production within their supply chains. All spatial analyses and maps were completed using ArcGIS v10.5.1 (ESRI 2017) and statistical analyses in R 3.4.3 (R Core Team 2017).

\subsection{ISIMIP scenario options}

Global gridded crop models (GGCMs) project crop yields at a high resolution over large areas. They are process-based crop models which use a combination of inputs such as weather and soil conditions, as well as plant-specific characteristics, to model crop parameters globally. For the agriculture sector, ISIMIP provides crop yield projections at a $0.5^{\circ}$ resolution under a range of climate change scenarios.

The ISIMIP Fast Track round (2012-2013), the most recent simulation round which includes agriculture as a climate-impact sector, provides data for fifteen crops and covers a range of different scenarios (see Table 1). Outputs from a number of different GGCMs (each

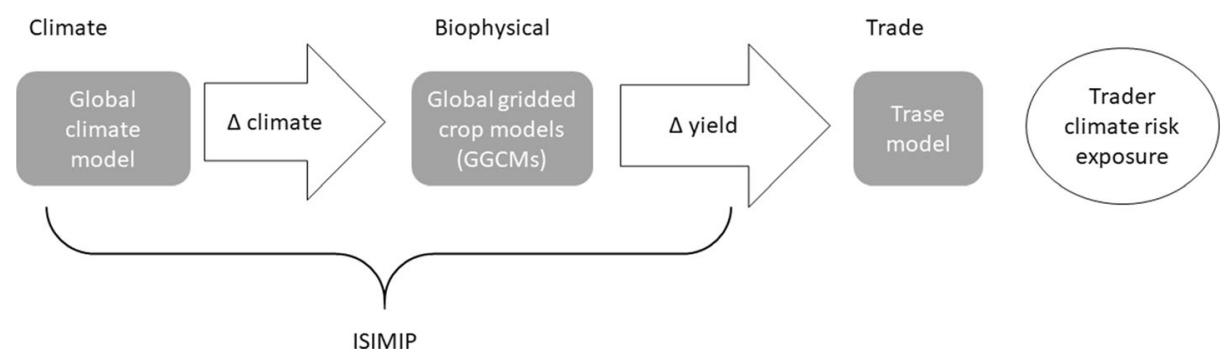

Fig. 1 Impact modelling chain: models and outputs used to estimate trader climate risk exposure. Shaded grey boxes represent the models used in our methodology, and shapes with no shading represent outputs at each stage. Adapted from Nelson et al. (2014a) 
modelling between three and fifteen crops) are available for every year between 2004 and 2098 inclusive. To allow for comparison of projected yields across GGCMs, we selected a consistent scenario and the years 2006-2016 and 2045-2055 for analysis of the mid-term impacts of climate change relative to a baseline period (see Section 2.4). We chose scenarios that replicate current crop management conditions in order to project the impacts of climate change prior to adaptation.

\subsection{GGCM yield projections}

Whilst it was not within the scope of this paper to carry out a full GGCM intercomparison exercise (see supplementary material, Section S1, for further discussion of GGCM comparison and selection), we assessed each GGCM output for errors (e.g. missing gridcells, implausible yields, abnormally large yield differences across adjacent gridcells) in order to make sure the model was suitable for the crop and location of study. For each GGCM, we calculated mean modelled yield across 2006-2016 and mapped the results over the area of study to $0.5^{\circ}$ by $0.5^{\circ}$ gridcells (see Fig. S1, supplementary material). Models with insufficient coverage of the study area were excluded at this step, and for responses to other errors, see Section 2.4.

\subsection{Brazil soy yield projections}

We apply methods 2.2-2.3 described above within the specific context of the case study of Brazilian soy. Soy is modelled by seven different GGCMs in the ISIMIP Fast Track round (detailed in Table S1, supplementary material). These include three site-based crop models originally developed for field-scale applications (EPIC, GEPIC, pDSSAT), three agroecosystem models derived from global ecosystem models (LPJ-GUESS, LPJmL, PEGASUS) and one agro-ecological zone model (IMAGE). All seven GGCMs model actual yield except IMAGE and LPJ-GUESS which model potential yield (Müller et al. 2017). For the case study of Brazilian soy, we chose ISIMIP scenario variables to replicate current common growing conditions (Table 1, Section 2.2).

We selected the years averaged around 2011 and 2050 to analyze the mid-century effects of climate change. The year 2011 was chosen as the most recent year for which we could create a 10 -year average with current production data at the time of data preparation. The year 2050 was chosen to enable comparison with other climate change studies which often include results for 2050, and as an appropriate time-horizon for traders and policymakers.

The RCP4.5 pathway was chosen to represent moderate climate change which aligns with current international policy targets. It describes a stabilization scenario without overshoot to a total radiative forcing of $4.5 \mathrm{~W} / \mathrm{m}^{2}$ after 2100 (IPCC 2017). Under RCP4.5, the global average temperature in 2050 is expected to have increased by $1.0-1.6^{\circ} \mathrm{C}$ above pre-industrial levels

Table 1 ISIMIP scenario options and chosen variables

\begin{tabular}{lll}
\hline ISIMIP scenario options & Available variables & Case study variable(s) \\
\hline Years of analysis & $2004-2098$ & $2006-2016$ and 2045-2055 \\
Representative concentration pathway & $2.6 / 4.5 / 6.0 / 8.5$ & 4.5 \\
Global climate model & Five models available & HadGEM2-ES \\
Irrigation & Yes/no & No \\
$\mathrm{CO}_{2}$ effects & Yes/no & Yes \\
\hline
\end{tabular}


(Rogelj et al. 2012). Although the RCP4.5 pathway is optimistic on global greenhouse gas mitigation, there is debate over whether it would satisfy the Paris Agreement, with some stating that it is likely to exceed $2{ }^{\circ} \mathrm{C}$ by 2100 (Symon 2013) and others arguing that it will almost certainly limit warming to below $2{ }^{\circ} \mathrm{C}$ (Salawitch et al. 2017).

We selected the Hadley Centre Global Environment Model version 2 (HadGEM2-ES) as it is widely accepted and implemented in the climate modelling community and is simulated by all seven GGCMs included in this analysis.

Within the GGCMs, the irrigation and $\mathrm{CO}_{2}$ effect options were chosen to reflect the current production conditions of the case study crop and region. Model runs without irrigation were chosen (Table 1), since irrigation for soy in Brazil covers only approximately 5\% of the cultivated area (Sentelhas et al. 2015). As a C3 crop, soy is particularly sensitive to $\mathrm{CO}_{2}$ (Slingo et al. 2005), and therefore, $\mathrm{CO}_{2}$ fertilization effects were included in the chosen model outputs. We explore the uncertainties around $\mathrm{CO}_{2}$ fertilization effects for crops in Section 4.2.

We aggregated GGCM outputs to municipality level for integration with trade data and to compare 2011 modelled yields to observed yields. Municipality outlines often cross multiple raster grid squares (see Fig. S2, supplementary material, for municipality outlines), requiring a process of weighting all yield projections intersecting a municipality. For each GGCM, a land area-weighted mean of yields for each municipality was calculated as follows: mean yield data for 2006-2016 and mean yield data for 2045-2055 were converted from raster data to polygon shapefiles and intersected with municipality outlines. We then weighted each polygon's yield value by its area and calculated an area-weighted municipality-scale yield using all the polygons within each municipality. We assumed that crop-planted area is distributed equally throughout the municipality.

For municipalities where part of the area is covered by a gridcell with a null value, we calculated municipality-level yield by excluding null value polygons from the total municipality area. ISIMIP's results for the EPIC model run produced an output with null values for $19.10 \%$ of the total area of Brazil, and EPIC was therefore excluded from further analysis. The other six models also have some null values (mostly around the coastline), but they are relatively small compared with EPIC, covering 0.01\% (IMAGE), 0.05\% (GEPIC), $0.05 \%$ (LPJmL), $0.05 \%$ (pDSSAT), $0.45 \%$ (LPJ-GUESS) and $0.78 \%$ (PEGASUS) of Brazil. These six models were retained in the analysis, and null values were excluded at the aggregation step.

In some GGCM simulations for the 2006-2016 mean yield, yields of zero were erroneously modelled for municipalities with recorded crop harvests in 2006-2016. Erroneous yields of zero for 2006-2016 were modelled by PEGASUS (for the municipalities of Tavares, in Rio Grande do Sul, and Mostardas, in Rio Grande do Sul) and pDSSAT (Eldorado, in Mato Grosso do Sul). This error can occur where the GGCM gridcells do not fully cover the landmass of Brazil, and therefore leave a municipality blank. It can also occur where GGCM simulation resolution obscures field-level differences in environmental conditions (e.g. average conditions within a gridcell could be inhospitable to soy, but it may contain pockets where production is possible). In the case of these municipalities, we assumed no change in yield, and set projected 2045-2055 yield at the observed 2006-2016 mean yield.

\subsection{Trader climate risk exposure}

We define trader climate risk exposure as the product of projected yield changes and relative trade volumes sourced from the given areas of supply. 
For the latter, we used subnational trade data available through the Trase platform (Trase 2019). Trase uses a combination of publically available data sources to capture detailed trade flows from subnational production through to countries of import (Godar et al. 2015; Trase 2018). Individual supply chain actors are systematically linked to specific, subnational production regions for high deforestation-risk commodities, covering all the exports for a given commodity from a given country of production. Data is currently available at a subnational level for select countries and commodities, with new countries and commodities being added on a rolling basis.

Within the Trase datasets, some trade flows attributed to traders have an unknown municipality of production. These flows cannot be linked to future climate change yield projections, and we excluded them from the analysis. In the Trase data for our case study of Brazilian soy, $18 \%$ of total soy exports from Brazil in 2016 are not linked to a municipality of production, and these flows cannot be included in the analysis. For the top 10 exporters in 2016, which are presented in this paper, the figure for Trase unknowns is slightly lower, at $14 \%$ of total soy mass exported. The proportion of unknowns varies per crop and country context, but is expected to be reduced in future releases with subsequent iterations of each model.

To analyze the projected impact of climate change on each trader's current supply chain, we first created boxplots for the projected proportional change to yield (the ratio of the mean modelled yield for 2045-2055 to the mean modelled yield for 2006-2016, see Section 2.4) in each trader's source municipalities, repeated for each GGCM and trader combination. This retains the range in projected yield change, so it is possible to see the variation in climate change impacts projected for different municipalities in each trader's supply chain.

Secondly, we multiplied Trase's outputs for crop mass (raw crop equivalent) sourced by each trader from each municipality by the projected proportional yield change for that municipality. This resulted in an estimate for trader climate risk exposure. We repeated this calculation for each GGCM and trader combination.

\section{Results}

\subsection{Subnational climate change impacts on soy in Brazil}

Figure 2 maps the modelled change in soy yield between 2006-2016 mean yield and 20452055 mean yield per municipality for six GGCMs. Substantial variation between GGCM projections is apparent. For some models, there is a decrease in yield over the majority of Brazil (e.g. PEGASUS, GEPIC, IMAGE), whereas other models project an increase in yield for most of the country (e.g. LPJmL, LPJ-GUESS, pDSSAT).

In addition to the national picture, there are also specific localized examples where some models agree and others disagree. For example, the pDSSAT and PEGASUS maps show a zone of decreasing yields in the southern state of Rio Grande do Sul, but this pattern is not visible in any of the other maps. It is important to note that every model projects both yield increases and decreases within Brazil, so subnational variation is projected regardless of the GGCM chosen.

\subsection{Subnational sourcing patterns of traders}

Different soy traders operating in Brazil have different soy sourcing profiles (Fig. 3). For example, in 2016, Coamo bought 95\% of its Brazilian soy from Paraná, and Bianchini bought 

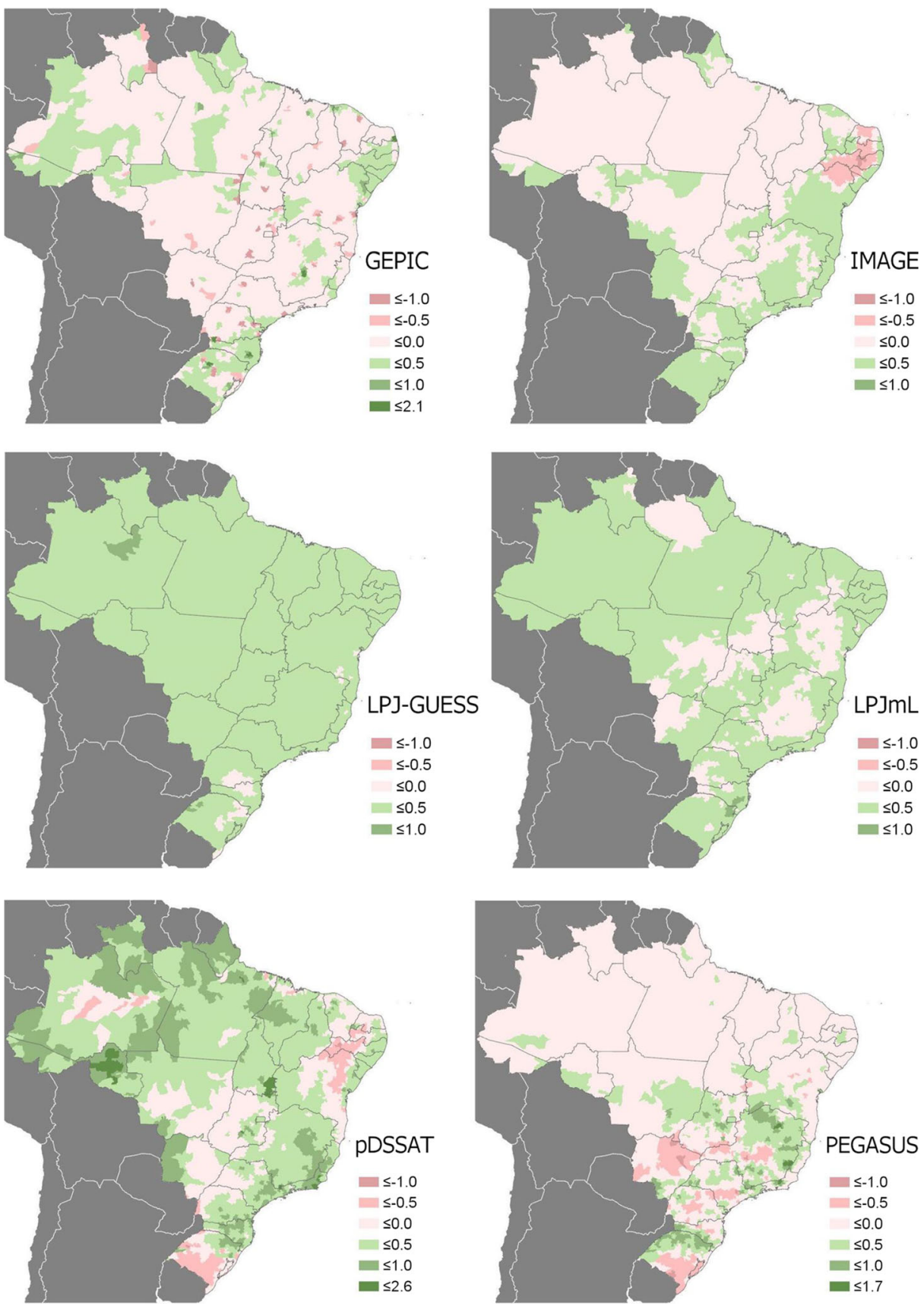

Fig. 2 Change in soy yield (tonnes per ha) per municipality between 2006-2016 mean yield and 2045-2055 mean yield, per GGCM. Plotted alongside state boundaries. Green gridcells indicate positive yield changes and red indicate negative 
94\% of its Brazilian soy from Rio Grande do Sul. Although there are some changes over time, these spatial sourcing patterns are relatively consistent for the preceding 10 years (see Fig. S3). Whilst many of the top 10 traders (ranked by tonnes of soy exported in 2016) buy from similar combinations of producing states, distinctive patterns can be observed in their relative sourcing from different regions - such as Amaggi, which sources a larger proportion from Mato Grosso (75\%) than the other top 10 traders, and Louis Dreyfus, which consistently bought a higher proportion from Goiás than any of the other top 5 traders (28\% in 2016, see Fig. S3 for 2006 and 2011).

\subsection{Trader climate risk exposure}

Figure 4 shows that each trader has a different risk exposure profile. Each boxplot represents a different crop model and trader combination, with colours denoting crop model, and plots are grouped by trader. Comparing bars of the same colour reveals the variation across traders for each GGCM. For example, using the pDSSAT model, Bianchini has a greater negative projected change in soy yield across municipalities in its supply chain than the other traders (a median of $-10 \%$, compared with medians of -1 to $+4 \%$ for the other traders). Figures 2 and 3 indicate that this is likely to be due to its reliance on buying soy from Rio Grande do Sul (Fig. 3) and the zone of yield decrease visible in that state on pDSSAT's yield change map (Fig. 2). The relevant data for trader risk exposure of Bianchini and Coamo are displayed together in Fig. S4, in the supplementary material.

Comparing the bars within each panel reveals the difference in yield projections between GGCMs for each trader (Fig. 4). As expected given the differences between the projected yield change maps (Fig. 2), projections for each trader contrast widely using different GGCMs. In Fig. 4, we see that this variation between different GGCMs is in many cases greater than the

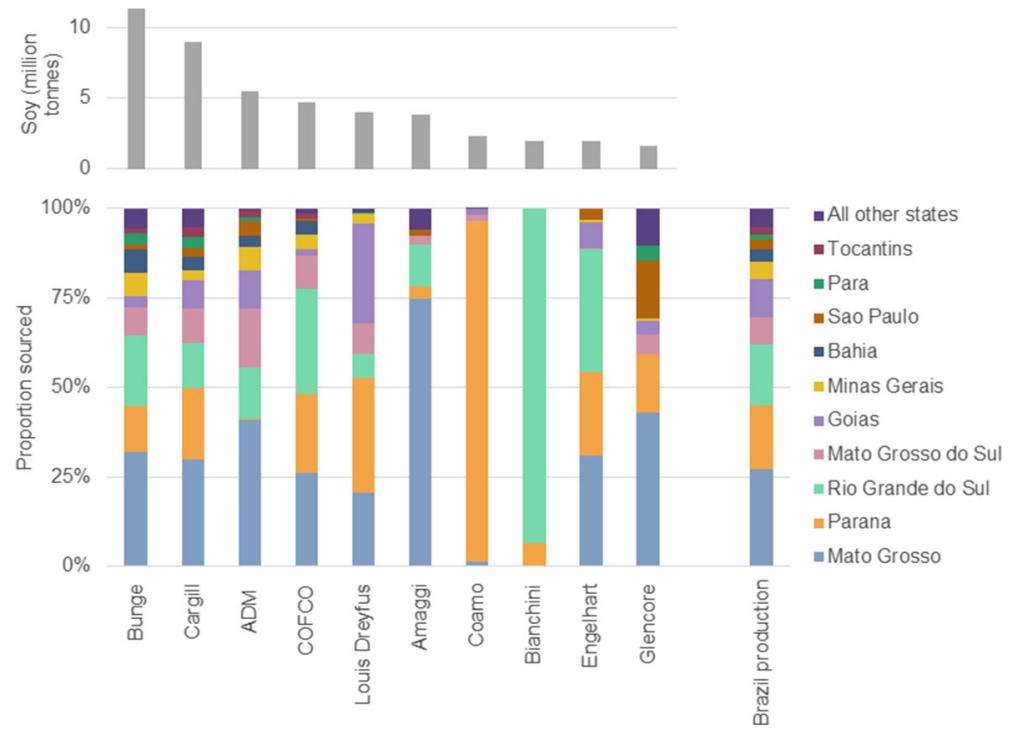

Fig. 3 Proportion of soy sourced from each state per trader, and total soy production per state, for 2016. Top 10 traders in 2016, in order of tonnes of soy exported, largest to smallest (Bunge to Glencore). This figure includes soy bought from known states but unknown municipalities (flows from unknown municipalities are not included in Fig. 4) 


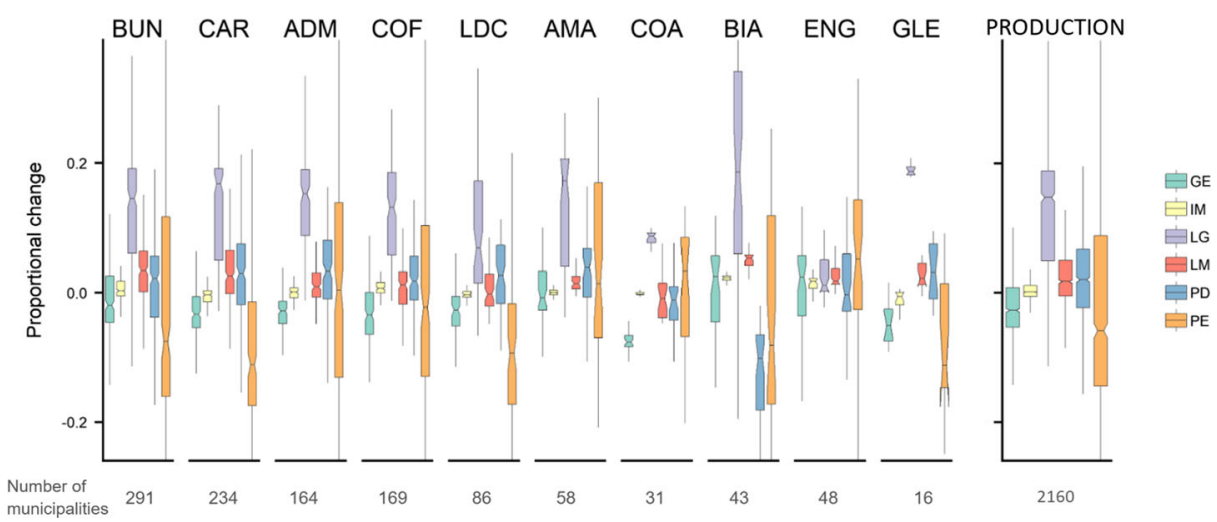

Fig. 4 Boxplots representing projected change in mean soy yield between 2006-2016 and 2045-2055 across municipalities supplying traders, per GGCM, with Brazil national soy production for comparison. Numbers below the panels represent the number of municipalities each trader sourced from in 2016 (and for Brazilian production the number of producing municipalities). Whiskers extend to the most extreme data point which is no more than 1.5 times the interquartile range, and some whiskers extend beyond the axis. Notches indicate the confidence interval around medians. Traders ordered by tonnes of soy exported in 2016, largest to smallest. Traders: Bunge (BUN), Cargill (CAR), Archer Daniels Midland (ADM), COFCO (COF), Louis Dreyfus (LDC), Amaggi (AMA), Coamo (COA), Bianchini (BIA), Engelhart (ENG), Glencore (GLE). GGCMs: GEPIC (GE), IMAGE (IM), LPJ-GUESS (LG), LPJmL (LM), pDSSAT (PD) and PEGASUS (PE)

variation caused by trader sourcing patterns as bars of the same GGCM across different traders often show more similar distributions than bars within a single trader's panel.

Traders may not source an equal proportion of soy from every municipality in their supply chain, and they will be more concerned about impacts in the municipalities which make up a larger proportion of their supply. For an estimate of total climate risk exposure, it is necessary to take the differences into account. When we multiply projected proportional yield change by the volume of trade flows in each municipality to estimate total trader climate risk exposure, we lose detail on the range in yield differences across municipalities, but gain information on the relative volumes of trade flows. Figure 5 shows that total trader climate risk exposure largely follows the medians displayed in Fig. 4. However, there are some differences, such as Coamo which has only one positive proportional change projected out of six GGCMs in Fig. 5 but a more varied picture in Fig. 4, and Bianchini where the pDSSAT projection is much more negative than the PEGASUS projection, despite very similar medians in Fig. 4 (see also projections for Coamo and Bianchini, Fig. S4).

\section{Discussion}

Using a combination of climate, crop and trade models, we demonstrate that adopting a subnational lens reveals differences in climate risk exposure between downstream actors, even when they source the same commodity from the same country. In the case study of Brazilian soy, we demonstrate that different subnational sourcing patterns lead to different levels of relative risk exposure for traders. Where, to the best of our knowledge, previous studies on transboundary climate risk have remained at the national level, our methodology offers an insight into subnational variation, which could help inform risk assessments and appropriate adaptation and planning decisions. In the following discussion, we address the results and 


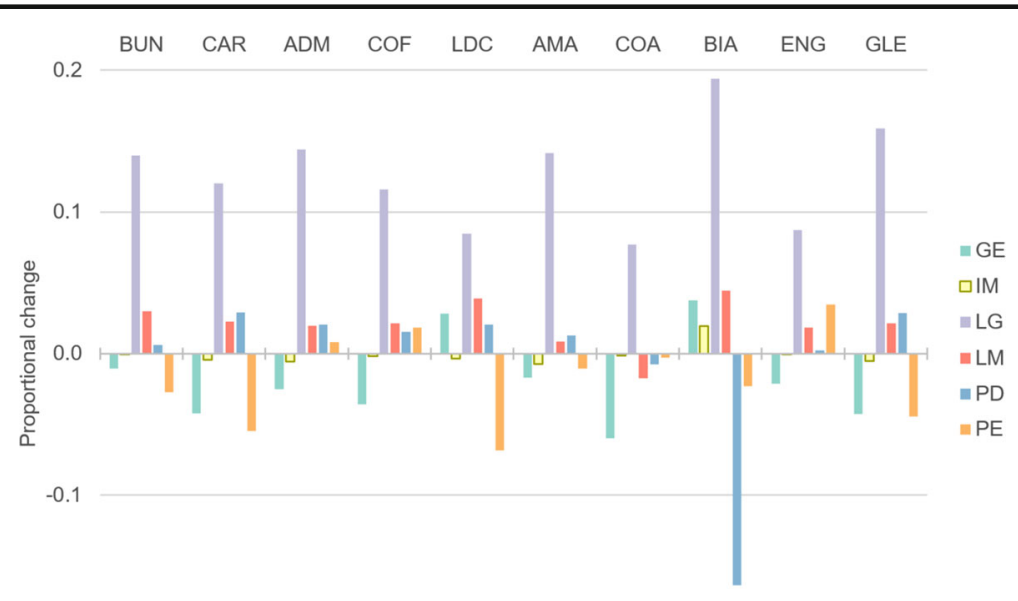

$-0.2$

Fig. 5 Total trader climate risk exposure between 2006-2016 and 2045-2055. Bars grouped by trader, colours denote GGCM. Traders ordered by tonnes of soy exported in 2016, largest to smallest. Traders: Bunge (BUN), Cargill (CAR), Archer Daniels Midland (ADM), COFCO (COF), Louis Dreyfus (LDC), Amaggi (AMA), Coamo (COA), Bianchini (BIA), Engelhart (ENG), Glencore (GLE). GGCMs: GEPIC (GE), IMAGE (IM), LPJ-GUESS (LG), LPJmL (LM), pDSSAT (PD) and PEGASUS (PE)

implications of the case study and reflect on working with GGCM data and avenues for future research.

\subsection{Subnational climate risk exposure for traders of Brazilian soy}

Whilst this method could be applied to any crop-country combination where appropriate GGCM and trade data are available, we apply it to the case study of commodity traders sourcing soy from Brazil. The biggest Brazilian soy traders source from a wide range of areas across Brazil, in proportions which approximately reflect the spatial patterns of production (see the top 5 traders in Fig. 3, Section 3.2). However, smaller traders generally have more distinct sourcing profiles (traders in 6th-10th place in Fig. 3, Section 3.2) and appear to consistently source from specific areas within Brazil's soy-producing regions (e.g. Amaggi, Coamo, Bianchini, Fig. S3).

In a country of Brazil's size, with distributed soy production, it is reasonable to assume that different levels of risk are associated with different areas. Our results suggest that this is the case: all GGCMs predict subnational variation in climate change impacts (Fig. 2, Section 3.1), in line with previous studies (Lobell et al. 2008; Osborne et al. 2013; Justino et al. 2013). Using our chosen parameters, each GGCM model projects both positive and negative yield changes within Brazil, although in the case of LPJ-GUESS, only a few gridcells are projected to experience yield losses. It is therefore plausible to suggest that, given the heterogeneous nature of sourcing patterns, some traders will be at a greater risk from climate change than others (see Fig. 4, Section 3.3).

In our case study, the most extreme levels of climate risk exposure (positive and negative) are projected for Bianchini, a trader which sources from a spatially concentrated subset of producing regions (see Fig. S3 and Fig. S6, supplementary material). Using the pDSSAT model, Bianchini is exposed to a relatively high level of risk as a result of a concentration of its 
source municipalities in Rio Grande do Sul (see Fig. 4, Section 3.3). However, a concentrated sourcing pattern could also be an advantage if the area is projected to see relatively high yield increases, as we can see for Bianchini under the LPJ-GUESS model (see Fig. 4, Section 3.3). Across a varied climate risk landscape, larger traders are more likely to be "buffered" from localized areas of extreme yields, due to distributed sourcing allowing for compensation of potential yield changes elsewhere in their supply chain.

For traders and other decision-makers, it is important to highlight the inconsistencies between crop models: the GGCMs included in this study do not reach consensus on future yield projections. Each trader has both positive and negative projections of climate risk exposure (Fig. 5, Section 3.3). GGCMs disagree both on the direction and on the magnitude of potential yield change (IMAGE projects a maximum percentage change of $2 \%$, whereas LPJ-GUESS projects a range of 8-19\%; see Fig. S5, supplementary material). Given the disagreement between GGCMs, the results should be interpreted as a range of potential scenarios rather than individual projections. The selection and use of GGCMs is discussed further in Section 4.2.

Whilst results are uncertain and further analysis would be required to translate results into real-world applications (see Section 4.3), these potential future scenarios could begin to aid downstream actors in assessing risks in their current spatial sourcing patterns, and inform decisions on future investments. Of the ten traders in this study, nine are linked to soy storage, crushing and refining facilities within Brazil (see Fig. S6, supplementary material), indicating that sourcing may be costly and difficult to shift and/or would require relatively long-term planning decisions to ensure that new investments are placed effectively. Whilst some assets may be located at ports, many assets are located close to the traders' particular sourcing areas, meaning that changes in productivity in regions of crop production are likely to have implications for the optimal placing of these investments. For example, Coamo is the only trader with five negative projections out of the six GGCM scenarios (all other traders have at least three positive scenarios; see Fig. 5, Section 3.3). It also sources over $90 \%$ of its soy from one state (Paraná; see Fig. 3) and owns over 100 soy storage, crushing and refining facilities in Brazil, of which close to $90 \%$ are located in the same state: Paraná (see Fig. S6, supplementary material). This spatial concentration of soy assets renders Coamo particularly exposed to the climate change impacts on soy yields in Paraná. If climate risk exposure data were incorporated into future infrastructure investment decision-making, it could help guide investments towards areas of Brazil where yields are expected to increase, although disagreements between GGCMs would need to be further investigated before actions are taken.

Each trader's risk exposure must be considered in the context of all traders; even a positive effect of climate change on yields could lead to a comparative disadvantage if yields increase to a greater magnitude in other areas of Brazil and other traders' areas of operation. This comparison would be further improved with data on climate risk to soy in other countries (Ray et al. 2019); global soybean-planted area is expected to expand (e.g. in Southern Africa; Gasparri et al. 2015) and climate change is predicted to increase soybean yield in mid- and high-latitude regions by the end of this century (Rosenzweig et al. 2014), and in Asia, central and eastern Europe and Canada by 2050 (Arnell et al. 2016). These areas could help meet increased demand for soybean, but agricultural expansion in Brazil and other countries brings its own risks, including the potential for deforestation, land ownership conflicts and loss of biodiversity. These tensions between supply and demand will be important for soybean-importing countries to monitor over the coming decades. 


\subsection{Use of GGCM projections}

Crop model selection is an important step in the assessment of climate impacts (Ruane et al. 2014), and depending on the parameters and mechanisms used to calculate crop yield, results differ between models. Several recent studies have carried out crop model intercomparisons, finding large uncertainties and biases and a "wide gulf" between plant science and crop models, in part due to the inevitable time lag required for the incorporation of new plant science knowledge into crop models (Fodor et al. 2017, p. 10). One method to account for model-related biases is to use crop model ensembles (e.g. Rosenzweig et al. 2014; Nelson et al. 2014a; Bassu et al. 2014), but a time lag remains for the incorporation of new plant science knowledge.

For example, crop models rarely incorporate current knowledge of plant responses to high atmospheric $\mathrm{CO}_{2}$ (Fodor et al. 2017), which plays an important role in the scenario outcomes for climate change impacts on crops (Fischer 2009). There are concerns that its positive effect has been exaggerated since it is difficult to reproduce in the field (Justino et al. 2013). Other studies suggest that its effect on yields could be reduced over long time horizons due to photosynthetic acclimation (Bunce 2000) or that exposure to high levels of $\mathrm{CO}_{2}$ could cause a deterioration in the quality of the yield (Blanc and Reilly 2017). The complexity of plant response to high $\mathrm{CO}_{2}$ remains unresolved and is a key factor of uncertainty for crop yield simulations. In response to these and other uncertainties, some caution is necessary when using and interpreting GGCM outputs.

Testing a GGCM's ability to model future yields is complex and is an area worthy of further attention. Since it is impossible to compare model outputs for future yields with observations, one approach is to measure a GGCM's ability to model current or historical observed yields. A previous crop model intercomparison study compared historic crop yield simulations to reference data for 1982-2005 and found that LPJmL had the highest correlation (0.82) for soybean yields in Brazil with historical reference data (Müller et al. 2017). For the GGCMs included in our study, we also carried out an exploratory comparison of modelled yields to historic yields averaged around the base year for our study of 2011 (see Section S1 and Figs. S1 and S7, supplementary material). However, this approach is problematic since observed data is affected by many factors that the GGCM yields do not model, such as specific management systems, extreme weather events, socio-economic factors, and pests and diseases. Therefore, big differences in yield values and distributions between modelled yields and observed yields can be expected and do not necessarily point to issues within the models per se. Furthermore, the ability to correctly model current yields does not guarantee an ability to predict future yields, especially in the context of a changing climate.

Comparison with the outputs of other papers is an alternative approach to assessing the suitability of GGCMs. For example, in a previous model-intercomparison study, LPJ-GUESS predicted the highest percentage change in soy production globally (Rosenzweig et al. 2014), which is consistent with the results of our case study (see Fig. S5, supplementary material). The same paper showed that GEPIC predicted negative percentage changes in production by 2050, also consistent with our findings for the majority of traders (see Fig. S5, supplementary material). These similarities suggest that different GGCMs are consistently optimistic or pessimistic in their predictions of crop yields, strengthening the argument for using a combination of GGCMs to represent alternative scenarios.

In many cases, the current disagreement between GGCM scenarios would prevent stakeholders from acting directly on the risk exposure results. Despite this disagreement for our case 
study of Brazilian soy, we include a range of subnational GGCM projections which highlight that - whatever the model choice - a traders' risk exposure is likely to differ based on their location of operations and in comparison with other traders. This fact would not be evident without models (crop yield projections and trade) applied at a subnational resolution, so whilst results presented are likely more complex (given their differences and spatial heterogeneity), they add significant value in comparison with perspectives that would be obtained via nationalscale analysis. Where yield projections calibrated for regional specificity exist for the chosen resolution of subnational sourcing and trade, these could be used in the place of GGCMs. However, GGCMs have the advantage of providing a globally consistent approach that can be aggregated to match trade data resolution in any country and provide the required subnational scale for differentiation of risk exposure between subnational supply chains. This will be important for allowing intercountry comparison at subnational scales as suitable trade information continues to emerge. As crop models continue to evolve and incorporate new plant science, new yield projection data could be incorporated in our methodology to give stakeholders greater confidence in preparing for future scenarios.

\subsection{Future research}

With the caveat of GGCM uncertainty, one of the applications for climate risk exposure data could be anticipating and preparing for potential land use change. A shift in the areas of suitability for soy production may cause a displacement of other crops or heighten agricultural competition for protected land, as protected areas have historically been established in locations that minimize conflict with agriculturally suitable lands (Venter et al. 2017). In addition, unprotected land may also be threatened and there are particular fears for the Cerrado, a global biodiversity hotspot adjacent to the Amazon with low legal protection and currently $88.4 \%$ of its remaining lands suitable for growing soy (Strassburg et al. 2017). By indicating where future pressures might occur, these results can help inform discussions between stakeholders, and to prepare responses to these risks. This is a key concern for consumer countries and companies, particularly those with zero deforestation commitments (Pasiecznik and Savenije 2017).

Alternatively, in areas of projected soy yield losses, soy producers in Brazil could respond with a range of adaptation strategies, and this potential must be considered in order to not overestimate expectations of yield losses under a future with climate change (Mendelsohn et al. 1994). Depending on the driver of yield losses (e.g. water deficit or heat stress), strategies could include planting improved soy varieties, shifting planting dates, changing the number of fallow years, developments in soil management and increasing the use of irrigation (White et al. 2011; Justino et al. 2013). Traders which identify particular risks to the producing municipalities in their supply chains may choose to invest in targeted adaptation activities to reduce their supply risks. Both adaptation activities and the expansion of crops into new areas entail potential costs to traders, and future research could explore the estimation of such costs and potential effects on soy prices.

Although we focus on the chronic and relatively direct risks from gradual changes in mean climatic conditions, future work could incorporate the impacts of other variables likely to affect yields at a subnational level. For example, climate change may affect the dynamics between pests and diseases and plants, but currently there is no general consensus on how to model these dynamics (Luck et al. 2011). Climate change could also alter weather variability and extreme weather events, both of which could have significant impacts on crop yields (Ray 
et al. 2015; Lesk et al. 2016). However, existing data on extreme weather events is rare because, by definition, they occur infrequently and therefore sample sizes can only be small (Bailey et al. 2015).

By incorporating several GGCMs in this study, we explore GGCM-level uncertainty. However, uncertainties in global climate models and climate change scenarios could also lead to different yield projections (Osborne et al. 2013). Climate change is already moving faster than is predicted in the RCP4.5 emissions scenario (Rogelj et al. 2012; Copernicus 2017), meaning the estimates of climate change impacts presented here are likely to be conservative. Future research could test different climate scenarios and use different global climate models to estimate transnational climate risk.

Finally, although we have projected climate risks only up to 2050, the effects of climate change will continue to evolve beyond the first half of the century and are expected to have a worsening impact on agriculture thereafter (Fischer 2009). The impacts of climate change are predicted to become more extreme by 2100 , with a maximum change in production of $\pm 60 \%$ (Rosenzweig et al. 2014). For long-term planning, decision-makers should therefore make use of projections across several points in time.

\section{Conclusions}

This paper contributes to a growing body of work assessing transnational risks associated with the impact of climate change on agriculture. Using a subnational resolution, the results highlight that different traders could be exposed to different levels of risk, even if sourcing the same commodity from the same country. Secondly, our results show that crop models can produce very different results for future yields under the same climate change scenario, illustrating the importance of considering a range of crop models. The considerable divergence in model outputs makes the risk assessment more complex than if consistent outputs were produced across models, and further work investigating these differences would help decisionmakers interpret and respond to their projected risk exposure.

The methodology used here can be implemented for any crop and country combination depending on data availability, and in the context of wider food security issues, it will be important to apply these methods to other producers and downstream actors in the food system. Subnational trade datasets already link production to countries of first import and are currently being developed in new country and commodity contexts, increasing the potential for future analyses (Trase 2019). Although beyond the scope of the current paper, it may be that for these different contexts GGCMs perform more consistently, leading to a clearer estimate of risk exposure.

Studies of climate change impacts on crops at a subnational scale allow policymakers and other stakeholders to be better prepared for climate change risks. Ultimately, crop production and food security are a product of much more than "climatic determinism" (Brown and Funk 2008). Nevertheless, the pressures of climate change will play an important role in agricultural change into the indefinite future. By advancing the tools available to measure transnational climate risk, we contribute to the discussion of how, where and by whom climate risk may ultimately be felt.

Acknowledgements The authors wish to acknowledge Magnus Benzie, Lisa Emberson, Eleanor Jew and two anonymous reviewers for constructive comments in relation with the research presented here. 
Funding E.S., S.A.C. and C.D.W. were supported by the IKnowFood project, funded by the UK Global Food Security program (Project BB/N02060X/1), and the Cascades project, funded by the EU Horizon 2020 programme (Grant agreement ID 821010). All authors were supported by the Trase initiative, funded by the Gordon and Betty Moore Foundation (Grant 7703), and the Norwegian Ministry of Climate and Environment (Grant 18/3871).

\section{Compliance with ethical standards}

Conflict of interest The authors declare that they have no conflict of interest.

Open Access This article is licensed under a Creative Commons Attribution 4.0 International License, which permits use, sharing, adaptation, distribution and reproduction in any medium or format, as long as you give appropriate credit to the original author(s) and the source, provide a link to the Creative Commons licence, and indicate if changes were made. The images or other third party material in this article are included in the article's Creative Commons licence, unless indicated otherwise in a credit line to the material. If material is not included in the article's Creative Commons licence and your intended use is not permitted by statutory regulation or exceeds the permitted use, you will need to obtain permission directly from the copyright holder. To view a copy of this licence, visit http://creativecommons.org/licenses/by/4.0/.

\section{References}

Arnell NW, Brown S, Gosling SN, Gottschalk P, Hinkel J, Huntingford C, Lloyd-Hughes B, Lowe JA, Nicholls RJ, Osborn TJ, Osborne TM, Rose GA, Smith P, Wheeler TR, Zelazowski P (2016) The impacts of climate change across the globe: a multi-sectoral assessment. Clim Chang 134:457-474

Bailey R, Benton TG, Challinor A, Elliott J, Gustafson D, Hiller B, Jones A, Jahn M, Kent C, Lewis K, Meacham T, Rivington M, Robson D, Tiffin R and Wuebbles DJ (2015). Extreme weather and resilience of the global food system. Final Project Report from the UK-US Taskforce on Extreme Weather and Global Food System Resilience, The Global Food Security programme, UK

Bassu S, Brisson N, Durand J, Boote K, Lizaso J, Jones JW, Rosenzweig C, Ruane AC et al (2014) How do various maize crop models vary in their responses to climate change factors? Glob Chang Biol 20:23012320. Available at:. https://doi.org/10.1111/gcb.12520

Benzie M, Hedlund J and Carlsen H (2016). Introducing the transnational climate impacts index: indicators of country-level exposure - methodology report. Stockholm Environment Institute, Working Paper 2016-07

Blanc E, Reilly J (2017) Approaches to Assessing Climate Change Impacts on Agriculture: An Overview of the Debate. Review of Environmental Economics and Policy 11(2):247-257

Brown ME, Funk CC (2008) Food security under climate change. Science 319:580-581. Available at. https://doi. org/10.1126/science. 1154102

Bunce JA (2000) Acclimation of photosynthesis to temperature in eight cool and warm climate herbaceous C3 species: temperature dependence of parameters of a biochemical photosynthesis model. Photosynth Res 63(1):59-67. Available at. https://doi.org/10.1023/A:1006325724086

Bunge (2019). Climate: Adapting to a changing world. Available at: https://www.bunge. com/sustainability/climate [Accessed 26th March 2019]

Cargill (2019a). Climate Change: reducing our impact while helping farmers adapt to a changing climate. Available at: https://www.cargill.com/sustainability/priorities/climate-change [Accessed 26th March 2019]

Cargill (2019b). Cargill celebrates 15 years of operation in Santarém. Available at: https://www.cargill.com. br/pt_BR/2018/santarem [Accessed 24th June 2019]

Challinor AJ, Watson J, Lobell DBM, Howden SM, Smith DR, Chhetri N (2014) A meta-analysis of crop yield under climate change and adaptation. Nat Clim 4:287-291. https://doi.org/10.1038/nclimate2153

Challinor AJ, Adger WN, Benton TG (2017) Climate risks across borders and scales. Nat Clim Chang 7:621623. https://doi.org/10.1038/nclimate3380

Ciplet D, Adams KM, Weikmans R, Roberts JT (2018) The transformative capability of transparency in global environmental governance. Global Environ Politics 18(3):130-150. https://doi.org/10.1162/glep_a_00472

Copernicus (2017). Earth on the edge: record breaking 2016 was close to $1.5^{\circ} \mathrm{C}$ warming. [Online]. Copernicus. Available at: https:/climate.copernicus.eu/news-and-media/press-room/press-releases/earth-edge-recordbreaking-2016-was-close-15\%C2\%B0c-warming [Accessed 15 August 2017] 
Croft SA, West CD, Green JMH (2018) Capturing the heterogeneity of sub-national production in global trade flows. J Clean Prod 203:1106-1118. Available at. https://doi.org/10.1016/j.jclepro.2018.08.267

D’Odorico P, Carr JA, Laio F, Ridolfi L, Vandoni S (2014) Feeding humanity through global food trade. Earth's Future 2(9):458-469. Available at. https://doi.org/10.1002/2014ef000250

EEA (2018) National climate change vulnerability and risk assessments in Europe, 2018. Publications Office of the European Union, Luxembourg, p 2018

ESRI (2017) ArcGIS Desktop: Release 10.5.1. Environmental Systems Research Institute, Redlands

Fader M, Gerten D, Krause M, Lucht W, Cramer W (2013) Spatial decoupling of agricultural production and consumption: quantifying dependences of countries on food imports due to domestic land and water constraints. Environ Res Lett 8(1):014046. https://doi.org/10.1088/1748-9326/8/1/014046

Fischer, G. (2009). World Food and Agriculture to 2030/50: how do climate change and bioenergy alter the longterm outlook for food, agriculture and resource availability? Expert Meeting on How to Feed the World in 2050. Food and Agriculture Organization of the United Nations. Economic and Social Development Department. International Institute for Applied Systems Analysis, Laxenburg

Fodor N, Challinor A, Droutsas I, Ramirez-Villegas J, Zabel F, Koehler A, Foyer CH, (2017) Integrating Plant Science and Crop Modeling: Assessment of the Impact of Climate Change on Soybean and Maize Production. Plant and Cell Physiology 58(11):1833-1847

Gasparri NI, Kuemmerle T, Meyfroidt P, le Polain de Waroux Y, Kreft H (2015) The emerging soybean production frontier in Southern Africa: conservation challenges and the role of south-south telecouplings. Conserv Lett 9(1):21-31

Godar J, Persson UM, Tizado EJ, Meyfroidt P (2015) Towards more accurate and policy relevant footprint analyses: tracing fine-scale socio-environmental impacts of production to consumption. Ecol Econ 112:2535. Available at. https://doi.org/10.1016/j.ecolecon.2015.02.003

Hedlund J, Fick S, Carlsen H, Benzie M (2018) Quantifying transnational climate impact exposure: New perspectives on the global distribution of climate risk. Global Environmental Change 52:75-85

IPCC (2014). Climate change 2014: synthesis report. Contribution of Working Groups I, II and III to the Fifth Assessment Report of the Intergovernmental Panel on Climate Change. [Core writing Team, R.K. Pachauri and L.A. Meyer (eds.)]. IPCC, Geneva

IPCC (2017). Scenario process for AR5 - representative concentration pathways (RCPs) [online]. Last updated: 3 August 2017. Available at: http://sedac.ipcc-data.org/ddd/ar5_scenario process/RCPshtml [Accessed 7 August 2017]

ISIMIP (2018). The Inter-Sectoral Impact Model Intercomparison Project. Available at: https:/www.isimip.org/ [Accessed 5 March 2018]

Justino F, Oliveira E, Rodrigues R, Gonçalves P, Souza P, Stordal F, Marengo J, Silva T, Delgado R, Lindemann D, Costa L (2013) Mean and interannual variability of maize and soybean in Brazil under global warming conditions. Am J Clim Chang 2(4):237-253. Available at. https://doi.org/10.4236/ajcc.2013.24024

Lesk C, Rowhani P, Ramankutty N (2016) Influence of extreme weather disasters on global crop production. Nature 529(7584):84-87

Lobell DB, Burke MB, Tebaldi C, Mastrandrea MD, Falcon WP, Naylor RL (2008) Prioritizing climate change adaptation needs for food security in 2030. Science 319:607-610. Available at. https://doi.org/10.1126 /science.1152339

Luck J, Spackman M, Freeman A, Trębicki P, Griffiths W, Finlay K, Chakraborty S (2011) Climate change and diseases of food crops. Plant Pathol 60:113-121. Available at:. https://doi.org/10.1111/j.13653059.2010.02414.x

Mendelsohn R, Nordhaus WD, Shaw D (1994) The impact of global warming on agriculture: a Ricardian analysis. Am Econ Rev 84(4):753-771

Müller C, Elliott J, Chryssanthacopoulos J, Arneth A, Balkovic J, Ciais P, Deryng D, Folberth C, Glotter M, Hoek S, Iizumi T, Izaurralde RC et al (2017) Global gridded crop model evaluation: benchmarking, skills, deficiencies and implications. Geosci Model Dev 10:1403-1422. Available at. https://doi.org/10.5194/gmd-10-1403-2017

Nelson GC, Valin H, Sands RD, Havlík P, Ahammad H, Deryng D, Elliott J, Fujimori S, Hasegawa T, Heyhoe E, Kyle P, Von Lampe M et al (2014a) Climate change effects on agriculture: economic responses to biophysical shocks. PNAS 111(9):3274-3279. Available at. https://oi.org/10.1073/pnas.1222465110

Nelson GC, van der Mensbrugghe D, Ahammad H et al (2014b) Agriculture and climate change in global scenarios: why don't the models agree. Agric Econ 45:85-101. Available at. https://oi.org/10.1111/agec.12091

Osborne T, Rose G, Wheeler T (2013) Variation in the global-scale impacts of climate change on crop productivity due to climate model uncertainty and adaptation. Agric For Meteorol 170:183-194. Available at. https://doi.org/10.1016/j.agrformet.2012.07.006

Pasiecznik N, Savenije H (2017) Zero deforestation: a commitment to change. Tropenbos International, Wageningen

Pirrong C (2014). The economics of commodity trading firms. Trafigura. Available at: https:/www.trafigura. com/media/1364/economics-commodity-trading-firms.pdf [Accessed 20 May 2019]

R Core Team (2017) R: a language and environment for statistical computing. R Foundation for Statistical Computing, Vienna Available at: https://www.R-project.org. Accessed 14 Sept 2020 
Ramirez-Villegas J, Challinor AJ, Thornton PK, Jarvis A (2013) Implications of regional improvement in global climate models for agricultural impact research. Environ Res Lett 8(2):024018. Available at. https://oi. org/10.1088/1748-9326/8/2/024018

Ray DK, Gerber JS, MacDonald GK, West PC (2015) Climate variation explains a third of global crop yield variability. Nat Commun 6:5989. Available at. https://doi.org/10.1038/ncomms6989

Ray DK, West PC, Clark M, Gerber JS, Prishchepov AV, Chatterjee S (2019) Climate change has likely already affected global food production. PLoS One 14(5):e0217148. Available at. https://doi.org/10.1371/journal. pone. 0217148

Rogelj J, Meinshausen M, Knutti R (2012) Global warming under old and new scenarios using IPCC climate sensitivity range estimates. Nat Clim Chang 2:248-253. Available at. https://doi.org/10.1038/nclimate1385

Rosenzweig C, Elliott J, Deryng D, Ruane AC, Müller C, Arneth A, Boote KJ, Folberth C, Glotter M, Khabarov N, Neumann K, Piontek F, Pugh TAM, Schmid E, Stehfest E, Yang H, Jones JW (2014) Assessing agricultural risks of climate change in the 21st century in a global gridded crop model intercomparison. Proc Natl Acad Sci 111(9):3268-3273. Available at. https://doi.org/10.1073/pnas.1222463110

Rosenzweig C, Arnell NW, Ebi KL, Lotze-Campen H, Raes F, Rapley C, Stafford Smith M, Cramer W, Frieler K, Reyer CPO, Schewe J, van Vuuren D, Warszawski L (2017) Assessing inter-sectoral climate change risks: the role of ISIMIP. Environ Res Lett 12:010301. Available at. https://oi.org/10.1088/1748-9326/12/1/010301

Ruane AC, McDermid S, Rosenzweig C, Baigorria GA, Jones JW, Romero CC, Cecil LD (2014) Carbontemperature-water change analysis for peanut production under climate change: a prototype for the AgMIP Coordinated Climate-Crop Modeling Project (C3MP). Glob Chang Biol 20:394-407. Available at. https://doi.org/10.1111/gcb.12412

Salawitch, R., Canty, T., Hope, A., Tribett, W. and Bennett, B. (2017). Paris Climate Agreement: Beacon of Hope. Springer Climate. Available at: https://doi.org/10.1007/978-3-319-46939-3

Samora, R. (2018). Brazil to pass U.S. as world's largest soy producer in 2018. Reuters. Available at: https://www.reuters.com/article/us-brazil-soy-usa/brazil-to-pass-u-s-as-worlds-largest-soy-producer-in2018-idUSKBN1IC2IW [Accessed 23 May 2018]

Sentelhas PC, Battisti R, Câmara GMS, Farias JRB, Hampf AC, Nendel C (2015) The soybean yield gap in Brazil - magnitude, causes and possible solutions for sustainable production. J Agric Sci 153:1394-1411. Available at. https://doi.org/10.1017/s0021859615000313

Slingo JM, Challinor AJ, Hoskins BJ, Wheeler TR (2005) Introduction: food crops in a changing climate. Philos Trans R Soc B 360:1983-1989. Available at. https://doi.org/10.1098/rstb.2005.1755

Strassburg BBN, Brooks T, Feltran-Barbieri R, Iribarrem A, Crouzeilles R, Loyola R, Latawiex AE, Oliveira Filho FJB, Scaramuzza CAM, Scarano FR, Soares-Filho B, Balmford A (2017) Moment of truth for the Cerrado hotspot. Nat Ecol Evol 1(4):0099. Available at. https://doi.org/10.1038/s41559-017-0099

Symon C (2013). Climate change: action, trends and implications for business. The IPCC's Fifth Assessment Report, Working Group 1. Climate everyone's business

Tai APK, Martin MV, Heald CL (2014) Threat to future global food security from climate change and ozone air pollution. Nat Clim Chang 4:817-821. Available at. https://doi.org/10.1038/nclimate2317

Tao F, Yokozawa M, Zhang Z (2009) Modelling the impacts of weather and climate variability on crop productivity over a large area: a new process-based model development, optimization, and uncertainties analysis. Agric For Meteorol 149(5):831-850. Available at. https://doi.org/10.1016/j.agrformet.2008.11.004

Thornton PK, Ericksen PJ, Herrero M, Challinor AJ (2014) Climate variability and vulnerability to climate change: a review. Glob Chang Biol 20:3313-3328. Available at. https://doi.org/10.1111/gcb.12581

Trase (2018). Supply chain mapping in Trase: summary of data and methods. Trase

Trase (2019). Transparent supply chains for sustainable economies (Trase). Available at: www.trase.earth [Accessed 4 July 2019]

Venter O, Magrach A, Outram N, Klein CJ, Di Marco M, Watson JEM (2017) Bias in protected-area location and its effects on long-term aspirations of biodiversity conventions. Conserv Biol 32(1):127-134. Available at. https://doi.org/10.1111/cobi.12970

Warszawski L, Frieler K, Huber V, Piontek F, Serdeczny O, Schewe J (2014) The Inter-Sectoral Impact Model Intercomparison Project (ISI-MIP): Project framework. Proceedings of the National Academy of Sciences 111(9):3228-3232

Wheeler T, von Braun J (2013) Climate change impacts on global food security. Science 341:508-513. Available at. https://doi.org/10.1126/science. 1239402

White JW, Hoogenboom G, Kimball BA, Wall GW (2011) Methodologies for simulating impacts of climate change on crop production. Field Crop Res 124:357-368. Available at. https://doi.org/10.1016/j. fcr.2011.07.001

Publisher's note Springer Nature remains neutral with regard to jurisdictional claims in published maps and institutional affiliations. 